\title{
Diagnóstico prenatal de trombohematoma subcoriónico masivo (mola de Breus)
}

\author{
Sonia de Miguel M. ${ }^{1}$, Cristina Álvarez C. ${ }^{1}$, Paula Suárez M. ${ }^{1}$, Sergio Gutiérrez G. ${ }^{1}$, \\ Pascual Escudero V. ${ }^{1}$, José Ignacio González M.1 \\ ${ }^{1}$ Servicio de Ginecología y Obstetricia, Hospital Clínico Universitario de Valladolid. Valladolid, España.
}

\section{RESUMEN}

El trombohematoma subcoriónico masivo o Mola de Breus, por ser éste el autor que lo describió por primera vez en abortos, es un hematoma subcorial de al menos $1 \mathrm{~cm}$ de grosor que ocupa al menos, el $50 \%$ de la superficie fetal. Suele asociar una alta morbimortalidad fetal y perinatal, en forma de abortos, retraso del crecimiento intrauterino, muerte intrauterina, desprendimiento de placenta normalmente inserta y recién nacidos de bajo peso, generalmente pretérminos. Esta entidad debe diferenciarse de otros procesos que pueden asentar bajo la placa corial, hacia la superficie fetal como: corioangioma, depósitos de fibrina y trombosis del espacio intervelloso. Se han intentado postular mecanismos que pudieran causar dicha circunstancia, sin que por el momento podamos definir factores de riesgo médicos que claramente predispongan a padecer esta entidad. El objetivo de describir estos dos casos clínicos diagnosticados en 2013 es resaltar que, gracias a la sospecha ecográfica de un trombohematoma subcoriónico masivo, podemos estudiar la pieza de placenta y membranas tras la finalización de la gestación, con lo que obtendríamos así la confirmación anátomo-patológica, de otra manera esta información podría perderse.

\section{PALABRAS CLAVE: Trombohematoma subcoriónico masivo, mola de Breus, aborto tardío, retraso del crecimiento intrauterino, diagnóstico prenatal}

\section{SUMMARY}

The massive subchorionictrombo hematoma or Breus's Mola, this was the author who first described it in miscarriages, is a subchorionic hematoma at least $1 \mathrm{~cm}$ in thickness which occupies at least $50 \%$ of the fetal surface. Usually associated with high fetal and perinatal morbidity and mortality, as miscarriages, intrauterine growth retardation, stillbirth, placental abruption and low birth weight, preterm generally. This entity should be distinguished from other processes that can seat under the chorionic plate to the fetal surface as chorioangioma, fibrin deposition and thrombosis intervillous space. They have tried to apply mechanisms that could cause such a circumstance, but for now we don't define medical risk factors that predispose clearly suffer from this entity. In order to describe these two cases diagnosed in 2013 is to emphasize that thanks to the sonographic suspicion of a massive subchorionic trombohematoma, can study the piece of placenta and membranes after the end of pregnancy, so it would provide pathologic confirmation, otherwise this information could be lost.

KEY WORDS: Massive subchorionictrombo hematoma, Breus's mola, late miscarriage, intrauterine growth retardation, prenatal diagnosis 


\section{INTRODUCCIÓN}

Las anomalías macroscópicas de la placenta pueden asociarse a una amplia variedad de efectos obstétricos desfavorables, debido a diferentes mecanismos patológicos, como insuficiencia útero-placentaria, hemorragia de vasos fetales, hemorragia retroplacentaria, trastornos de los vasos maternos, enfermedad trofoblástica gestacional, corioangioma, placenta previa increta y un amplio espectro de hemorragia dentro de la placenta.

Grandes áreas de hemorragia en el espacio subcoriónico fueron descritas inicialmente por Breus (año 1892) en abortos del primer trimestre (1). Posteriormente la mayoría de las publicaciones en relación a la mola de Breus o trombohematoma subcoriónico (THS), término con el que se denomina actualmente la entidad, se refieren a descripción de casos o pequeñas series.

El pronóstico tras la sospecha ecográfica de este hallazgo, varía según el tamaño, localización, características maternas y Doppler fetoplacentario, pudiendo conducir a abortos espontáneos, retraso del crecimiento intrauterino (RCIU), muerte fetal, mortalidad perinatal, abruptio de placenta y nacidos vivos de bajo peso generalmente pretérminos.

En esta comunicación describimos 2 casos observados en el año 2013, con distinto resultado obstétrico. En ellos se sospechó ecográficamente un THS, gracias a lo cual pudo realizarse la confirmación anátomo-patológica.

\section{Casos clínicos (Tabla I)}

Caso clínico 1. Primigesta de 27 años con gestación única espontánea de $13^{+6}$ semanas, que acude al servicio de urgencias por metrorragia del segundo trimestre. Como antecedentes personales refiere, peritonitis por apendicitis perforada y conización cervical con asa de diatermia (H-SIL), con posterior seguimiento cito-histológico sin lesiones. Fuma 3 a 4 cigarros/día. Los controles fueron normales, con ecografía de las 12 semanas acorde, translucencia nucal de $1,6 \mathrm{~mm}(<\mathrm{p} 99)$ y tamizaje combinado de primer trimestre de bajo riesgo para trisomía 21 (1:5466) y trisomía 18 (<1:100000). La determinación plasmática de $\beta$-HCG libre fue 0,909 MoM y la de PAPP-A 0,578 MoM. Estudio serológico negativo para virus hepatotropos, toxoplasma y $\mathrm{VIH}$ e inmune para rubéola. La ecografía evidencia un feto vivo con longitud cráneo-raquis de $75,7 \mathrm{~mm}$ (acorde para $13^{+5}$ semanas), cantidad normal de líquido amniótico y placenta en cara posterior previa oclusiva total, con zona eco mixta subamniótica de $60 \mathrm{~mm}$ de grosor, ocupando un $50 \%$ de la superficie placentaria fetal. Tras 72 horas de ingreso en reposo y observación, pese a disminuir el sangrado genital, se comprueba ecográficamente ausencia de latido cardiaco fetal, por lo que se inicia maduración cervical con prostaglandina $\mathrm{E} 1$ vaginal para evacuar el útero, que se logra con éxito. El resultado anátomo-patológico mostró un feto masculino de $8,5 \mathrm{~cm}$ de longitud, sin anomalías anatómicas visibles y un cordón con 3 vasos sin alteraciones. La placenta, de $10 \mathrm{~cm}$ de longitud máxima, macroscópicamente presenta gran hematoma subcoriónico que la microscopía informa como hematoma subcorial y que ocupa prácticamente la totalidad de la superficie placentaria (hematoma subcorialMola de Breus con desprendimiento prematuro de placenta). Pasadas 12 semanas post-aborto, se descartaron trombofilias y síndrome antifosfolípido.

Tabla I

RESUMEN DE ANTECEDENTES OBSTÉTRICOS DE LOS CASOS CLÍNICOS

\begin{tabular}{|c|c|c|}
\hline Variable & Caso 1 & Caso 2 \\
\hline Edad (años) & 27 & 39 \\
\hline Paridad & Primigesta & Primigesta \\
\hline Hábitos tóxicos & Fumadora de 3-4 cigarrillos/día & Fumadora de 5 cigarrillos/día \\
\hline Trombofilia & No & Mutación MTHFR homocigota \\
\hline PAPP-A sérica primer trimestre & $0,578 \mathrm{MoM}$ & $0,17 \mathrm{MoM}$ \\
\hline Cariotipo fetal prenatal & No & $46 X Y$ \\
\hline $\mathrm{RCIU}$ & No & $\mathrm{Si}$ \\
\hline Edad gestacional al diagnóstico & $13+6$ semanas & $21+0$ semanas \\
\hline Doppler AU & - & Flujo diastólico ausente \\
\hline Edad gestacional de finalización & $14+2$ semanas & $25+5$ semanas \\
\hline Resultado obstétrico & Aborto espontáneo segundo trimestre & Muerte intraútero $25+5$ semanas \\
\hline Tamaño ecográfico THS (mm) & 60 & 85,6 \\
\hline
\end{tabular}


Caso clínico 2. Primigesta de 39 años con gestación única tras técnica de reproducción asistida (FIV-TE) y diagnóstico de RCIU a las $21^{+4}$ semanas. Como antecedentes personales destacan: distrofia simpático refleja, síndrome de Raynaud, trombofilia por mutación del gen MTHFR homocigota (síndrome antifosfolípido negativo). Fuma 5 cigarrillos al día. Desde el inicio de la gestación ha recibido tratamiento con ácido acetilsalicílico 100 mg/día, enoxaparina 40 Ul/día y levofolinato cálcico $7,5 \mathrm{mg} /$ día. En primer trimestre se obtuvo un tamizaje combinado de bajo riesgo para trisomía 21 (1:970) y alto riesgo para trisomía 18 (1:220, punto de corte 1:270), con $\beta$-HCG libre 0,23 MoM, PAPPA 0,17 MoM y translucencianucal 0,6 $\mathrm{mm}(<\mathrm{p} 99)$. Se practicó una amniocentesis genética con resultado normal (46 XY). Tras diagnóstico de RCIU a las 21 semanas, se descarta infección feto-materna por citomegalovirus y preeclampsia (proteinuria 24 horas: $157 \mathrm{mg}$ ). A las 23 semanas ecográficamente se observa un peso fetal estimado de $276 \mathrm{~g}$ (percentil 0) y oligoamnios. La placenta en cara anterior-fondo presenta una imagen compatible con hematoma subcoriónico de 7,2 cm de grosor, que ocupa más del $50 \%$ de la superficie placentaria fetal sin vascularización Doppler (Figura 1). El estudio Doppler feto-placentario mostró signos de redistribución hemodinámica y de compromiso subagudo fetal (ductus venoso con contracción atrial reversa, IPACM $<$ p5 y flujo diastólico ausente en arteria umbilical). Con $25^{+3}$ semanas, acude al hospital por dinámica uterina y sangrado genital escaso oscuro, objetivándose ecográficamente un feto vivo de 340 $\mathrm{g}$, anhidramnios y la imagen placentaria anteriormente descrita. Se inicia tocolisis intravenosa con atosiban, neuroprotección fetal con sulfato de magnesio intravenoso y maduración pulmonar fetal con dos dosis de betametasona intramuscular (pauta rápida). Tras 48 horas de tocolisis, se comprueba latido cardiaco fetal ausente y se asiste al parto espontáneo de feto, placenta y membranas en bloque. Se obtiene feto masculino de $290 \mathrm{~g}$ y placenta de $360 \mathrm{~g}$ con hematoma subcoriónico (Figura 2). El resultado anátomo-patológico de placenta y membranas informa de gran hematoma en el espacio intervelloso placentario con áreas de organización, que desplaza las vellosidades y diseca la placa coriónica, compatible con THS masivo (mola de Breus). El feto es macroscópicamente normal con retraso de crecimiento para la edad gestacional y signos de aspiración de líquido amniótico.

\section{DISCUSIÓN}

Los casos expuestos son excepcionales por su presentación y por el diagnóstico prenatal del THS, ya que lo más frecuente es el diagnóstico histológico casual tras un aborto de primer trimestre.

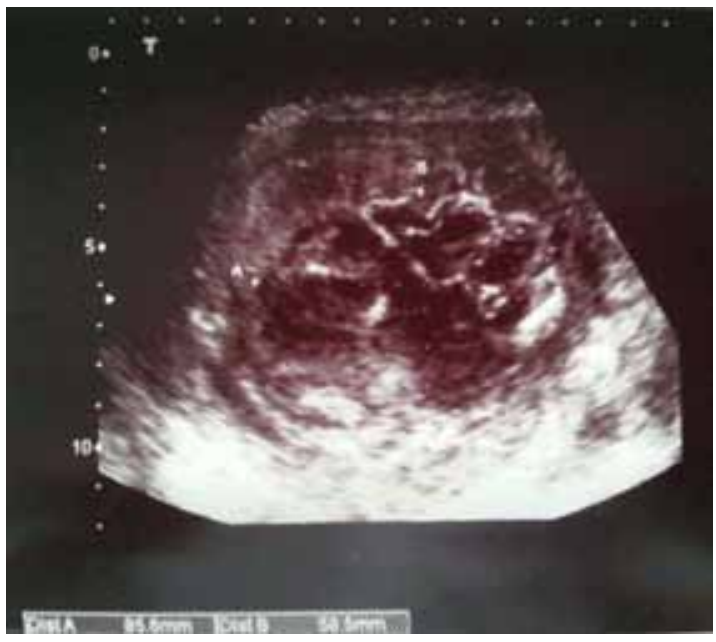

Figura 1. Caso 2: Trombohematoma subcoriónico de $85,6 \times 58,5 \mathrm{~mm}$.

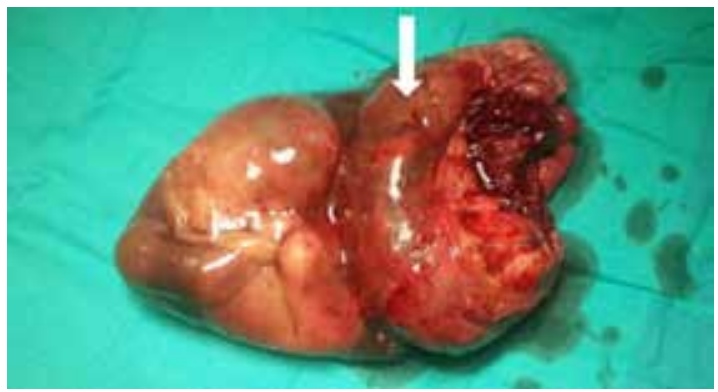

Figura 2. Feto, membranas y placenta en bloque. La flecha señala el trombohematoma subcoriónico.

Reportamos nuestros 2 casos clínicos para destacar la importancia de sospechar ecográficamente esta entidad, debido a su baja frecuencia, para así evaluar placenta y membranas, obteniendo la confirmación anátomo-patológica.

EI THS se describe como una imagen ecográfica eco mixta en la escala de grises, no vascularizada y ubicada en la placa corial. Los criterios diagnósticos son: grosor mayor de $1 \mathrm{~cm} \mathrm{(2)} \mathrm{y} \mathrm{ocu-}$ par un $50 \%$ o más de la superficie fetal placentaria (3). Tras la sospecha ecográfica deben descartarse procesos que pueden asentar en el área subcorial, como corioangioma, depósitos de fibrina y trombosis del espacio intervelloso.

Los corioangiomas son tumores vasculares intraplacentarios que pueden sobresalir a la 
superficie fetal y presentar vascularización con Doppler color (4). Los depósitos subcoriónicos de fibrina son áreas ecográficas hipo o anecogénicas, con flujo lento en su interior y la trombosis intervellosa aparece como una lesión hipo o anecogénica intraplacentaria que puede extenderse al espacio subcoriónico (4). Si se presentan dudas diagnósticas y para diferenciarlo de las entidades previas, puede realizarse Resonancia Magnética (3).

Se han descrito tasas de supervivencia variables, del 30\% para Shankiln y Scott (5) y del 50\% para Alanjari y cols (3), lo cual no ha podido demostrarse en nuestros casos, ya que uno fue una pérdida espontánea del segundo trimestre y el otro un nacido muerto con extrema prematuridad y bajo peso. Las causas de mortalidad se han relacionado con la prematuridad extrema y con el RCIU con Doppler anormal de la arteria umbilical (AU) (3).

Así se han propuesto dos mecanismos de producción del RCIU: uno debido a insuficiencia úteroplacentaria con Doppler anormal de la AU y otro debido a que el acúmulo de sangre materna en el trombohematoma podría comprimir la placenta y/o los vasos umbilicales fetales (6). Por lo que se ha establecido que presentar un Doppler normal de la AU presumiría un buen pronóstico del THS.

Además del THS, otras anomalías de la placenta y membranas que puedan asociarse pueden contribuir a la mortalidad perinatal (3), como la formación anormal de vellosidades coriales, infartos úteroplacentarios o un cordón hiperenrollado.

Dado que se han visto involucrados muchos mecanismos patológicos en los casos con malos resultados obstétricos, parece improbable que estos mecanismos puedan revertirse con heparina, tal como ocurrió en nuestro caso clínico 2.

EI RCIU se relaciona frecuentemente con trombosis e infartos placentarios y débilmente con trombofilias. Así, la hemorragia placentaria no se considera, intuitivamente, una parte dominante de la patología placentaria en el RCIU (7). Además las lesiones placentarias del segundo trimestre son más frecuentemente causadas por hemorragias que por infartos placentarios (8).

De nuestros dos casos, la paciente 2 era portadora de una trombofilia, y a pesar de tratamiento con heparina de bajo peso molecular a dosis profiláctica desde el primer trimestre, no se evitó la aparición del THS. Los resultados del estudio de trombofilia y síndrome antifosfolípido a las 12 semanas del aborto en la paciente 1 , fueron negativos.

En un estudio amplio de cohortes se encontró que la combinación de niveles en sangre materna bajos de PAPP-A (Pregnancy-associated plasma protein A) y elevados de AFP (alfa fetoproteína), confería un $40 \%$ de exceso de riesgo de muerte intraútero y un $10 \%$ de exceso de riesgo de $\mathrm{RCIU}$ en poblaciones no seleccionadas (9). En nuestro caso 2, hallamos una PAPP-A baja en el primer trimestre con cariotipo en líquido amniótico normal. Los orígenes del desarrollo del THS en la gestación temprana, comenzando con niveles disminuidos de PAPP-A, parecen contener una base genética (10).

\section{CONCLUSIÓN}

No parecen existir por el momento, factores de riesgo médicos que predispongan a esta condición. La importancia de esta entidad radica en sospecharla prenatalmente, ya que la orientación diagnóstica permitirá al patólogo la confirmación de la presencia simultánea de áreas de trombosis y de hemorragia desplazando el tejido corial normal.

\section{REFERENCIAS}

1. Breus C. Tuberose Subchoriale Haematom der Decidua. Leipzig. Deuticke. 1892.

2. Thomas D, Makhhoul J, Müller C. Fetal growth retardation due to massive subchorionic thrombohematoma: report of two cases. J Ultrasound Med 1992;11(5):245-7.

3. Alanjari A, Wright E, Keating S, Ryan G, Kingdom J. Prenatal diagnosis, clinical outcomes, and associated pathology in pregnancies complicated by massive subchorionic thrombohematoma (Breus' mole). Prenatal Diagnosis 2013;33(10):973-8.

4. Tema 10. Ecografía de la placenta. En: Fleischer, Manning, Jeanty, Romero. Ecografía en Obstetricia y Ginecología. 6 $6^{\underline{a}}$ edición. Madrid: Editorial Marban, 2002:195-224.

5. Shanklin DR, Scott JS. Massive subchorial thrombohaematoma (Breus' mole). Br J ObstetGynaecol 1975;82(6):476-87.

6. Nishida N, Suzuki S, Hamamura $\mathrm{Y}$, Igarachi $\mathrm{K}$, et al. Massive subchorionic hematoma (Breus' Mole) complicated by intrauterine growth retardation. J Nippon Med Sch 2001;68(1):54-7.

7. Franco $\mathrm{C}$, Walker M, McLeod A, et al. Placental infarction and thrombophilia. Obstet Gynecol 2011;117(4):929-34.

8. Kingdom JC, Walker M, McLeod A, et al. Unfractionated heparin for second trimester placental insufficiency: a pilot randomized trial. J Thromb Haemost 2011;9(8):1483-92.

9. Smith GC, Shah I, Nelson SM, et al. Pregnancy-associated plasma protein $A$ and alpha-fetoprotein and prediction of adverse perinatal outcome. Obstet Gynecol 2006;107(1):161-6.

10. Monkley SJ, Delaney SJ, Wainwright BJ, et al. Targeted disruption of the Wnt2 gene results in placentation defects. Development 1996;122(11):3343-53. 